\title{
Modeling Cardiomyopathies in a Dish: State-of-the-Art and Novel Perspectives on hiPSC-Derived Cardiomyocytes Maturation
}

\author{
Francesco Lodola ${ }^{1, *}\left(\mathbb{D}\right.$, Verónica Celeste De Giusti ${ }^{2} \mathbb{D}$, Claudia Maniezzi $^{1}{ }^{\mathbb{D}}$, Daniele Martone ${ }^{1} \mathbb{D}$, Ilaria Stadiotti ${ }^{3}$, \\ Elena Sommariva ${ }^{3}$ and Angela Serena Maione ${ }^{3, *}$ \\ 1 Department of Biotechnology and Biosciences, University of Milano-Bicocca, Piazza della Scienza, 2, Ed U3, \\ 20126 Milan, Italy; claudia.maniezzi@unimib.it (C.M.); daniele.martone@unimib.it (D.M.) \\ 2 Centro de Investigaciones Cardiovasculares, Facultad de Ciencias Médicas, Universidad Nacional de La \\ Plata-CONICET, La Plata 1900, Argentina; degiustiveronica@gmail.com \\ 3 Vascular Biology and Regenerative Medicine Unit, Centro Cardiologico Monzino IRCCS, 20138 Milan, Italy; \\ ilaria.stadiotti@ccfm.it (I.S.); elena.sommariva@ccfm.it (E.S.) \\ * Correspondence: francesco.lodola@unimib.it (F.L.); angela.maione@ccfm.it (A.S.M.)
}

check for

updates

Citation: Lodola, F.; De Giusti, V.C.; Maniezzi, C.; Martone, D.; Stadiotti, I.; Sommariva, E.; Maione, A.S.

Modeling Cardiomyopathies in a Dish: State-of-the-Art and Novel Perspectives on hiPSC-Derived Cardiomyocytes Maturation. Biology 2021, 10, 730. https://doi.org/ 10.3390/biology10080730

Academic Editor: Vincenzo Lionetti

Received: 30 June 2021

Accepted: 24 July 2021

Published: 30 July 2021

Publisher's Note: MDPI stays neutral with regard to jurisdictional claims in published maps and institutional affiliations.

Copyright: (c) 2021 by the authors. Licensee MDPI, Basel, Switzerland. This article is an open access article distributed under the terms and conditions of the Creative Commons Attribution (CC BY) license (https:/ / creativecommons.org/licenses/by/ $4.0 /)$.
Simple Summary: Cardiomyopathies modeling is greatly smoothened by the technological advances made in the use of human induced pluripotent stem cells derived cardiomyocytes (hiPSC-CMs). Despite the advantages of allowing to model patient specific disease, hiPSC-CMs still show a degree of maturity comparable to fetal CMs. In this perspective, we discuss different methods to improve hiPSC-CMs maturity, and to create cardiomyopathy-specific models, allowing the assessment of relevant phenotypes. In addition, current limitations and required evolutions in cardiomyopathy disease modeling are addressed.

Abstract: The stem cell technology and the induced pluripotent stem cells (iPSCs) production represent an excellent alternative tool to study cardiomyopathies, which overcome the limitations associated with primary cardiomyocytes (CMs) access and manipulation. CMs from human iPSCs (hiPSC-CMs) are genetically identical to patient primary cells of origin, with the main electrophysiological and mechanical features of CMs. The key issue to be solved is to achieve a degree of structural and functional maturity typical of adult CMs. In this perspective, we will focus on the main differences between fetal-like hiPSC-CMs and adult CMs. A viewpoint is given on the different approaches used to improve hiPSC-CMs maturity, spanning from long-term culture to complex engineered heart tissue. Further, we outline limitations and future developments needed in cardiomyopathy disease modeling.

Keywords: hiPSC-CMs; cardiomyopathies; cardiovascular disease modeling; patient-specific medicine; stem cell maturation

\section{Introduction}

Cardiomyopathies are inherited cardiac conditions basically classified as myocardial disorders in which the heart muscle is structurally and functionally abnormal in the absence of ischaemic heart disease [1]. Therefore, the inherited cardiomyopathies are usually classified based on morphological alterations or electrical alterations. In particular, structural cardiomyopathies have historically been classified according to phenotypic features in different main categories: hypertrophic, dilated, arrhythmogenic, and restrictive $[1,2]$. Channelopathies are likewise grouped as arrhythmic disorders and ascribed to altered ion channel function or intracellular calcium handling disorder, causing electrical instability, and leading to malignant arrhythmias [3-5]. The main cardiac channelopathies are long QT syndrome (LQTS), short QT syndrome (SQTS), Brugada syndrome (BrS), and catecholaminergic polymorphic ventricular tachycardia (CPVT). 
An adult human heart is made up of different cell types essential for proper cardiac function. The most substantial volume is covered by cardiomyocytes (CMs) surrounded by highly specialized cells like fibroblasts, endothelial cells, and vascular cells [6-8]. Nonmyocyte cells are crucial for tissue homeostasis and cell-cell interaction based on their role in maintaining the structure, mechanical and electrical heart functions as occurs for fibroblasts and mesenchymal stromal cells [9-11].

The use of primary CMs for biochemical experiments is mostly limited by the cell number that can be isolated from mammalian species and by the restricted ability for $\mathrm{CM}$ division in culture and have a limited lifetime in vitro. In addition, cardiac biopsies are rarely available as a source for CMs. The limitations associated with adult CM manipulation have been balanced by stem cell technology and the induced pluripotent stem cells (iPSCs) production. They represent a useful and versatile tool to study cardiomyopathies based on their ability to differentiate in several cell types, including cardiac ones that are genetically identical to the cells of origin. Methods for controlling hiPSCs reprogramming and differentiation have been greatly improved over the past decade [12,13]; in particular, great efforts have been made to improve the maturity of iPSC-derived CMs (iPSC-CMs) which represent a major asset for cardiovascular diseases modeling and for personalized and precision medicine [14].

The iPSCs features make them highly suitable for generating "disease-in-a-dish" models: (i) the genetic profile of each iPSC line is analogous to founder cells; (ii) iPSCs allow the study of the genetic contribution to the disease phenotypes; (iii) by using genomeediting tools, such as CRISPR/Cas9 technology, it is possible to modify the genetic profile of iPSCs. The DNA sequence can be modified either by introducing a specific pathological mutation into control iPSC lines or by correcting a causative mutation [15].

In vitro single-cell models have been so far essential to the study of the pathogenic mechanisms underlying cardiomyopathies, but there are several limitations to their use. Isolated cells lack some important features of in vivo systems such as homo- and heterocellular interactions that are crucial for electrical properties contributing to the propagation of electrical impulses or for mechanical properties, creating a functional syncytium. Multicellular interactions in vivo may result in a worsening of a pathological phenotype that might not be evident in a single cell model. The implementation of a multicellular model can better recapitulate the complexity of the cardiomyopathies. The reciprocal interactions between myocyte and non-myocyte cell types in cardiomyopathies represent the first step towards personalized "heart in a dish" to model these diseases. From this perspective, we will focus the attention on hiPSC-CMs, we will critically discuss their current limitations and approaches to improve their maturation.

\section{Structural and Functional Features of hiPSC-Derived CMs}

hiPSC cardiomyogenic differentiation protocols have been developed in order to use hiPSC-CMs as a tool to study the basic mechanisms of human inherited cardiomyopathies. hiPSC-CMs exhibit heterogeneous phenotypes with diverse and specific characteristics depending on the differentiation protocol. A compelling issue that limits hiPSC-CMs benchto-bedside translation is whether in vitro hiPSC-CMs culture is actually able to recapitulate key-enabling electrophysiological and mechanical properties of mature cardiomyocytes. In the next paragraphs, we will discuss the principal structural, electrophysiological, $\mathrm{Ca}^{2+}$ handling, and bioenergetics properties of hiPSC-CMs in comparison to adult myocytes.

\subsection{Morphological Characteristics}

Morphology is an important aspect of the phenotype of a myocyte since it not only defines the structural scenario, but is also critical to determinate the cell's electrical and contractile properties. Adult CMs are typically rod-shaped with an average size of 100-150 $\mu \mathrm{m}$ in length and 15-30 $\mu \mathrm{m}$ in diameter [16]. They are highly organized and present a series of unique and defined structures that are vital for the proper functioning of the heart (Figure 1); the elaborate transverse-tubule (T-tubule) network and neighboring sarcoplas- 
mic reticulum (SR) is critical for beat-to-beat heart contraction while the large numbers of mitochondria make them highly fatigue-resistant [17]. Force development is strongly dependent on sarcomere content and myofibril distribution. The former is the repeating unit of the latter and constitutes the myocyte fundamental building block, responsible to convert the chemical energy of adenosine triphosphate (ATP) into mechanical work. Importantly, although CMs are individual units anatomically, they function as a syncytium and are coupled via polarized intercalated disc complexes, which allow action potential propagation with a propagation speed of $\sim 100 \mathrm{~cm} / \mathrm{s}$ [18].

Mature CMs

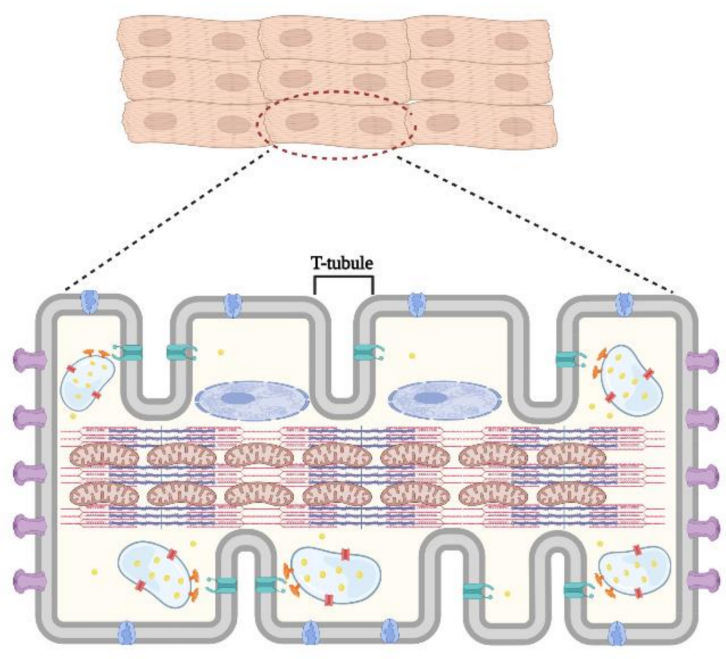

\section{hiPSC-CMs}

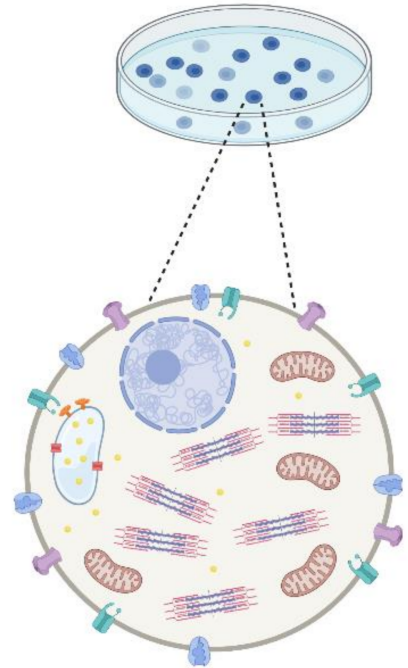
If LTCC 8 GJs I0 SERCA2a
(1) Nucleus
(1) Mitochondrion

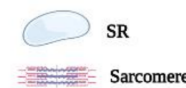

Figure 1. Principal morphological characteristics of the two cell categories: on the left a mature cardiomyocyte $(\mathrm{CM})$ with a typical rod-shaped structure and specific organization, an elaborate tubular network, a neighboring sarcoplasmic reticulum (SR), and large numbers of mitochondria. On the right, the human-induced pluripotent stem cells (hiPSC)-CM, which is smaller and more round-shaped, with an immature structure. Compared to adult CM, the hiPSC-CM presents (i) a lower co-localization of the L-type $\mathrm{Ca}^{2+}$ channel (LTCC) with the Ryanodine receptor type 2 (RyR2), (ii) a reduced number of gap junctions (GJs), (iii) an irregular distribution of $\mathrm{Ca}^{2+}$ ions and (iv) the T-tubular structure deficiency and immature sarcomere organization.

By contrast, as depicted in Figure 1, conventional hiPSC-CMs are smaller $(5-10 \mu \mathrm{m}$ in diameter), more round-shaped than the adult myocytes, and exhibit an immature irregular structure [19]. In particular, they lack an organized T-tubular network resulting in a poor colocalization of the L-type calcium channel Cav1.2 and Ryanodine receptor 2 (RyR2) [20]. This leads to an unequal distribution of $\mathrm{Ca}^{2+}$ release in the cytoplasm with global $\mathrm{Ca}^{2+}$ signals substantially slower than in adult CMs [20]. Furthermore, the gap junctions are less expressed and circumferentially distributed; therefore, the electrical conduction speed is an order of magnitude slower $(\sim 10 \mathrm{~cm} / \mathrm{s})$ than in adult cells. [21]. Sarcomere/T tubule irregularity also induces a disorganized contraction [22]. Moreover, hiPSC-CMs present less abundant mitochondria, localized mainly at the perinuclear space (occupying less than $5 \%$ of total cell volume) [21,23].

Altogether, these characteristics, that resemble those of rudimentary myocytes, lead to functional variances that could limit the potential use of hiPSC-CMs in disease modeling and therapeutic regeneration strategies. 


\subsection{Electrophysiological Properties}

The shape of the cardiac action potential is characterized by the different expression levels and functionality of voltage-gated ion channels, consistent with the ion currents across the plasma membrane of the myocytes [24]. Despite the discrepancies seen, some electrophysiological traits are common in hiPSC-CMs obtained with standard differentiation protocols. These cells present a maximum diastolic potential more depolarized $(\sim-60 \mathrm{mV})$ than adult CMs $(\sim-80 \mathrm{mV})$, mainly caused by a reduced outward flux of potassium correlated to low levels of inward rectifier current $\left(\mathrm{I}_{\mathrm{K} 1}\right)$ [25]. Furthermore, the decreased $\mathrm{I}_{\mathrm{K} 1}$, in conjunction with altered kinetics of the sodium channel Nav1.5, pours into a slower upstroke velocity $(10-60 \mathrm{~V} / \mathrm{s})$ compared to the human native counterpart, normally close to 200-300 V/s. Unlike the latter, the hiPSC-CMs exhibit also autorhythmicity; this is due to the higher levels of the pacemaker current $\mathrm{I}_{\mathrm{f}}$ (encoded by HCN4) that synergically interacts with the " $\mathrm{Ca}^{2+}$ clock" mechanism causing spontaneous activity in a similar way to what happens in sinoatrial nodal cells $[26,27]$. Other phenotypical hallmarks of hiPSC-CMs action potential waveform are: (i) a less prominent transient repolarization period (i.e., the notch, phase 1), attributable to a reduced transient outward potassium current [28]; (ii) anticipated repolarization due to the lack of the plateau phase (phase 2) and a fast phase 3, explicable with an altered balance between the inward currents, mediated by the L-type $\mathrm{Ca}^{2+}$ channels and the sodium-calcium exchanger $\left(\mathrm{I}_{\mathrm{NCX}}\right)$, and the outward currents, regulated by the rapid $\left(\mathrm{I}_{\mathrm{Kr}}\right)$ and slow $\left(\mathrm{I}_{\mathrm{Ks}}\right)$ delayed-rectifier potassium currents [29]. Nevertheless, differentiation methods have a major impact on hiPSC-CMs functional characteristics. Recently, groundbreaking approaches, which will be described in more detail later, allowed to obtain more physiological upstroke velocities and ventricular-like cells [30-32], thus further suggesting the compelling need to optimize differentiation protocols to obtain cells electrically closer to adult CMs.

\subsection{Excitation-Contraction Coupling and $\mathrm{Ca}^{2+}$ Handling}

The term excitation-contraction (EC) coupling describes the sequence of events that link $\mathrm{CM}$ excitation to contraction via intracellular $\mathrm{Ca}^{2+}$ release from the sarcoplasmic reticulum (SR) [33]. Briefly, in adult cardiac cells the action potential propagation along the transverse-axial tubular system leads to L-type $\mathrm{Ca}^{2+}$ channels opening on the plasma membrane, allowing $\mathrm{Ca}^{2+}$ entry from the extracellular space. This phenomenon triggers a further massive $\mathrm{Ca}^{2+}$ spill into the cytoplasm from the RyR2 on the SR, a phenomenon called $\mathrm{Ca}^{2+}$-induced $\mathrm{Ca}^{2+}$-release (CICR). The subsequent binding of cytoplasmic $\mathrm{Ca}^{2+}$ to the sarcomeric protein troponin $\mathrm{C}$ causes the conformational shift in tropomyosin, which ultimately translates to myofilament sliding and contraction. For relaxation to occur, $\mathrm{Ca}^{2+}$ must be removed from the cytoplasm, partly pumped back to the SR via the sarcoplasmic/endoplasmic reticulum $\mathrm{Ca}^{2+}$ ATPase 2a (SERCA2a) or out of the cell via the sodium-calcium exchanger (NCX). For the sake of completeness, the mitochondrial $\mathrm{Ca}^{2+}$ uniporter (MCU) and the sarcolemmal $\mathrm{Ca}^{2+}$ ATPase (PMCA) are also involved, but they play a minor role in the re-equilibration process [34].

The efficiency of these processes is strictly correlated not only to the expression of specific $\mathrm{Ca}^{2+}$-handling proteins but also to the specific spatial organization of the $\mathrm{Ca}^{2+}$ machinery [33]. In hiPSC-CMs, even if with different expression patterns, it has been observed the presence of functional EC coupling; however, the immature ultrastructural conformation (i.e., lack of T-tubules, neonatal-like sarcomere organization) strongly impairs its functionality causing strong repercussions on $\mathrm{Ca}^{2+}$ dynamics [20]. Moreover, contractile force is strictly dependent on a well-structured sarcomere network. The smaller length and the poor localization and alignment likely contribute to the overall lower force seen in hiPSC-CMs cells compared to adult ventricular CMs [20].

\subsection{Metabolism}

Cardiac metabolism dramatically changes during maturation. In adult myocytes, mitochondria cover one-third of the cell volume and are well organized in functional 
complexes among SR and myofibrils. The majority $(\sim 80 \%)$ of total energy consumption is supplied by $\beta$-oxidation of fatty acids and the ATP produced is used almost entirely to support contractile function and activity of transport ATPases. hiPSC-CMs behave more like immature myocytes with their metabolic consumption mainly relying on glycolysis which is relatively inefficient from an energetic standpoint [23].

\section{3. hiPSC-CMs State-of-the-Art and Novel Approaches for CMs Maturation}

The concept of "CM maturation" refers to the body of changes affecting cell structure, metabolism, functionality, and gene expression that happen during the transition from fetal to adult developmental state. In the next paragraph, we will discuss consolidated approaches and cutting-edge methodologies to pursue further maturation of hiPSC-CMs.

\subsection{Long-Term Culture and In Vivo Maturation}

The analysis of hiPSC-CMs obtained after different times of cardiac differentiation revealed increasing readouts of maturity in the function of the time and stimuli. However, even with long term culture maturation [35,36], hiPSC-CMs still retains some features of the embryonic phenotype such as the absence of a mature sarcomeric structure with $\mathrm{M}$-bands and a variable degree of myofibrillar organization, not comparable to the degree of maturity reached by transplanting them in rat neonatal hearts [37].

To date, the long-term 2D culture condition has been assessed up to one year of cardiac differentiation in order to test the hiPSC-CMs maturation enhancement [38,39]. Prolonged culture leads to a more mature phenotype of hiPSC-CMs in terms of morphology (larger cells), structure (visible sarcomeric organization), physiology $\left(\mathrm{Ca}^{2+}\right.$ handling properties), and electrophysiological features (increased action potential amplitudes) [39]. Notably, at 180 days of culture iPSC-CMs show more tightly packed myofibrils, and mature Z, A, $\mathrm{H}$, and I bands are visible. In contrast, the $\mathrm{M}$ bands that are essential in the sarcomere structure develop after 1 year of culture confirming that prolonged culture generates more mature CMs [38].

Considerable maturation of hiPSC-CMs was also observed after in vivo cell transplantation in several adult animals like mice, rats, and non-human primates [40-42]. After 3 months of transplantation, hiPSC-CMs were smaller than host cells but developed partially mature sarcomeric structures. The in vivo induction of hiPSC-CMs maturation seems to be greater in adult rat hearts than in neonatal rat hearts. However, this difference could also be ascribed to a different cell dose used in the two experiments [43]. The improvement of in vivo maturation rate also occurs for pathological phenotypes as proven for the arrhythmogenic right ventricular cardiomyopathy (ARVC) hiPSC-CMs engraftment. These hiPSC-CMs, transplanted into rat hearts, are highly analogous to adult ARVC CMs in terms of morphology, $\mathrm{Ca}^{2+}$ transients, contractility, and gene expression [37]. Thus, when subjected to the in vivo microenvironment, hiPSC-CMs are more mature than in vitro ones. This observation implies that by in vitro mimicking of in vivo conditions it should be possible to achieve improved maturation.

\subsection{Biochemical Cues}

Several studies have highlighted the importance of controlling metabolism to generate more mature stem cell models of human cardiovascular disease. Even if the regulators and the pathways involved have not yet been fully elucidated, there is strong evidence that this approach leads to gene expression patterns and functional properties more comparable to those of adult CMs. For example, treatment with the thyroid hormone tri-iodothyronine (T3), a hormone pivotal for optimal heart growth, drives structural and functional hiPSCCMs maturation, enhancing the size and sarcomere length as well as contractility capability, rates of $\mathrm{Ca}^{2+}$ release and re-uptake, and energy metabolism [44]. A further degree of maturation with functional T-Tubule development has been obtained by combining T3 with glucocorticoid hormones [45]. Rupert and Coulombe demonstrated that insulin-like growth factor-1 (IGF1), in synergy with neuregulin-1 (NRG1), enhanced proliferation, 
metabolic maturity, and the force-frequency relationship in hESC-Derived Engineered Cardiac Tissues [46]. A fundamental postnatal CM maturation step is the metabolic switch from glycolysis to fatty acid oxidation. Different studies have correlated culture medium properties and functional maturation of hiPSC-CMs. Indeed, several groups demonstrated that fatty acids supplementation improved hiPSC-CMs overall maturation [47-49], while a high-glucose media sorted the opposite effect. Kim and colleagues correlated this effect to the activation of the key metabolic regulator hypoxia-inducible factor $1 \alpha(\mathrm{HIF}-1 \alpha)$ and the consequent upregulation of lactate dehydrogenase A (LDHA) [50]. This evidence was corroborated by a more recent study that demonstrated how siRNA inhibition of HIF- $1 \alpha$ signaling shifted the cell metabolism towards glycolysis, thus highlighting how HIF- $1 \alpha-$ LDHA is a crucial pathway for cardiac maturation [51].

\subsection{Biophysical Stimuli}

Biophysical cues are an important tool to promote the maturation of hiPSC-CMs in vitro. Tuning substrate properties (i.e., stiffness, topography, and conductivity) has been widely exploited to modify cell behavior [52] mimicking the in vivo environment. Artificial polymers like polydimethylsiloxane (PDMS) have been used to create in vitro scaffolds that recapitulate the extracellular matrix (ECM) [53-55]. Lyra-Leite and colleagues' study indicate how mitochondrial architecture is dependent on cell shape and alignment and only moderately on matrix rigidity [56]. In agreement, the possibility to pursue a geometry-driven organization, forcing cell growth on islands of different shapes or with micro- and nano-patterned substrates, allowed regulating the structure and function of hiPSC-CMs [57-60]. In addition, electrical and mechanical stimuli have been applied to hiPSC-CMs sorting positive effects both on the structural and electrical degree of maturation [61-63]. Of recent interest, Dwenger et al. proposed optogenetics, a widely used biological technique that uses light to modulate molecular events through a genetically encoded component, to perform non-contact chronic optical stimulation in engineered cardiac tissues from hiPSC-CMs [64]. In comparison to the above-mentioned physical triggers, the use of light will represent a possible novel tool of modulation that offers unprecedented advantages, allowing to obtain a higher temporal and spatial selectivity net of lower invasiveness.

\subsection{Co-Culture and 3D Cultures}

Taken together, this information highlights the critical role of the microenvironment in increasing the phenotypic hallmarks of $\mathrm{CM}$ maturation that are lost within in vitro culture [65].

Moreover, the CMs fraction in the fetal heart gradually decreases with adult heart development due to the increased proliferation of non-CMs. In vitro data of 2D CMs and non-CMs co-culture indicate that the latest regulate $\mathrm{CM}$ maturation [66]. This regulation is possibly based on both direct cell-cell contact and on the paracrine factors secreted by non-CMs, modulating the CMs phenotype [67].

Cardiac fibroblasts and endothelial cells, for instance, can mimic biophysical and biochemical cues as a result of their ability to create the ECM and angiogenesis, respectively [68,69]. Nevertheless, 2D cultures cannot fully recapitulate the microenvironment, three-dimensional alignment, and the complex architectural network that occurs in an in vivo system. For instance, hiPSC-CMs in 3D culture develop greater structural, functional, and metabolic maturation than those in 2D culture [30,70-72] such as enhanced myofibrillar alignment and sarcolemma remodeling that lead to improved $\mathrm{Ca}^{2+}$ handling [73].

To date, different methods have been used to generate 3D cardiac cultures. The cardiac microtissues can be made by aggregation of hiPSC-CMs only or in combination with non-CMs in defined ratios through non-adhesive U-shaped wells, hanging drops, or agitation culture. Building of the 3D cardiac structure essentially involves two methods: scaffold-free, in which cells are seeded in culture medium, or scaffold-based, in which cells are seeded on a medium enriched in ECM/hydrogels or highly viscous chemicals and more 
complex engineering methods. By integrating tissue engineering and iPSC technology, it is possible to develop cardiac micro-physiological systems. Some examples of engineered heart tissues (EHT) include the use of biodegradable scaffolds for the generation of 3D microchannels coated with endothelial cells [74], the multiphoton-excited 3D printing technique to generate matrix scaffold with submicron resolution [75], and engineered cardiac patch with electronic properties [76].

A further approach to enhance maturation involves the formation of organoids, which provide a significant number of properties analogous to native heart tissue $[77,78]$. The combination of CMs and non-cardiac cells leads to the production of an aligned syncytium with tight cell-cell and cell-ECM connections characterized by a higher level of connexin-43 and improved electromechanical signal conduction [32]. In addition, the presence of matrixsecreting fibroblasts, endothelial cells, and muscle cells generates improved physiological stiffness and microvasculature within the 3D cardiac structures [79].

\section{Modeling Cardiomyopathies In Vitro}

Modeling cardiomyopathies in vitro is a challenge that is being faced by many investigators. Indeed, different issues make it difficult to address.

All cardiomyopathies show an undoubted genetic component, which is, however, incompletely understood, due to variable expressivity, incomplete penetrance, and genetic pleiotropy. In addition, a further complication comes from the existing phenotypic, and, in some cases, an underlying pathophysiological mechanism also overlaps different cardiomyopathies.

The development of hiPSC technology has provided the possibility to investigate the genetic aspects of cardiomyopathies in a patient- and mutation-specific scenario.

However, few reports revealed that epigenetic traits complicate the interpretation of iPSC-derived cell genetic-dependent readouts. Indeed, low passage iPSC retain residual DNA methylation modifications typical of their somatic tissue of origin, which influence their differentiation capabilities [80-82].

Given the electric etiology of the disorders, for channelopathy modeling, the main cell components are constituted by CMs [83-85]. Differently, structural cardiomyopathy modeling complex architecture requires the presence of several cell types. Indeed, over time, it assisted in disease modeling of increasing complexities, from the choice of the components to their patterning [86,87]. First of all, CM obtained from iPSC show an elevated degree of heterogeneity, spanning from atrial-like to nodal-like to ventricular-like [88]. Since cardiomyopathies mainly involve the ventricles, enrichment for ventricular CM may increase the proximity to the disease [89]. Further, to mimic ventricular tissue composition, researchers must aim to recapitulate the cell types, the correct amount, and distribution of adult ventricles [90]. An elaborate network of extracellular material, the ECM, either directly secreted by the cells present in the culture or provided as a support/anchoring scaffold, is also increasing the complexity of cardiomyopathy modeling, mimicking the mechanical, alignment, and chemical cues of the diseased microenvironment [91].

Different readouts are to be tested in different forms of cardiomyopathies: (i) electrophysiology and fields potentials can be monitored both in channelopathies and in structural cardiomyopathies and are essential to model arrhythmic dysfunction [92]; (ii) marker for altered pathways are readouts needed to understand the pathogenic mechanisms in every form of cardiomyopathies [93,94]; (iii) testing calcium handling dysregulation is important in channelopathies, as CPVT, but also in structural cardiomyopathies as Dilated Cardiomyopathy (DCM) and ARVC [95,96]; (iv) motion analysis and force measurements need to be tested mainly in the structural cardiomyopathies [97]; (v) similarly, the evaluation of ECM deposition is a common feature of pro-fibrotic tissue remodeling [69].

Other readouts are instead specific for certain cardiomyopathies, as occurs for fat accumulation in ARVC [98], or CM hypertrophy in HCM [99].

In addition, some cardiomyopathies (e.g., ARVC or CPVT) have a higher burden of arrhythmias and/or structural deterioration in the athletes. The effect of exercise can be modeled by mechanical stimuli or by pacing at increased frequencies [100]. 
However, iPSC-CMs modeling potential is hindered due to their relative immaturity at a structural, electrical, and metabolic level in comparison to adult human CMs (Figure 1). From this perspective, we have discussed cutting-edge approaches to ameliorate the hiPSCCMs degree of maturation so as to obtain a more reliable and accurate tool for disease modeling of cardiomyopathies (Figure 2). In particular, hiPSC-CMs maturation can be improved to a near-adult state by long-term culture [38]. Although the result is a highly mature cell in morphology and structure, its application to model cardiomyopathies is still hampered by the long lead time required for their production. The maturity reached by in vivo transplantation offers an overview of all the factors and environments that contribute to $\mathrm{CM}$ maturation (e.g., different cell type interaction, paracrine factors, biophysical stimuli) [40] that need to be recapitulated in vitro. Indeed, the use of biochemical and physical stimuli in vitro represents a tool with enormous potential. Inter alia, given the promising results obtained with optogenetics, it is conceivable that other geneless photomodulation approaches will gain momentum in forthcoming years. Examples may include photothermal stimulation [101], photoacoustic modulation [102], activation by electromagnetic field $[103,104]$, and use of exogenous light active materials $[105,106]$ as transducers of stimuli. In perspective, we believe that the latter seems particularly suitable to the scope thanks to the fact that they can be easily micro- and nano-structured through reasonably fast, repeatable and simple techniques [107-109], are highly biocompatible, and have proven capable of triggering pivotal biological targets (i.e., $\mathrm{Ca}^{2+}$ dynamics, ROS production) with unprecedented selectivity and spatial resolution [110-113]. Finally, co-cultures and $3 \mathrm{D}$ cultures provide an excellent resource to investigate myocytes and non-myocytes features and how their interplay may impact the disease phenotypes [32]. Both direct interactions and paracrine factors, as well as the contribution of ECM and/or scaffolds to shape the microtissues, can be determined to improve the differentiation protocols [114].

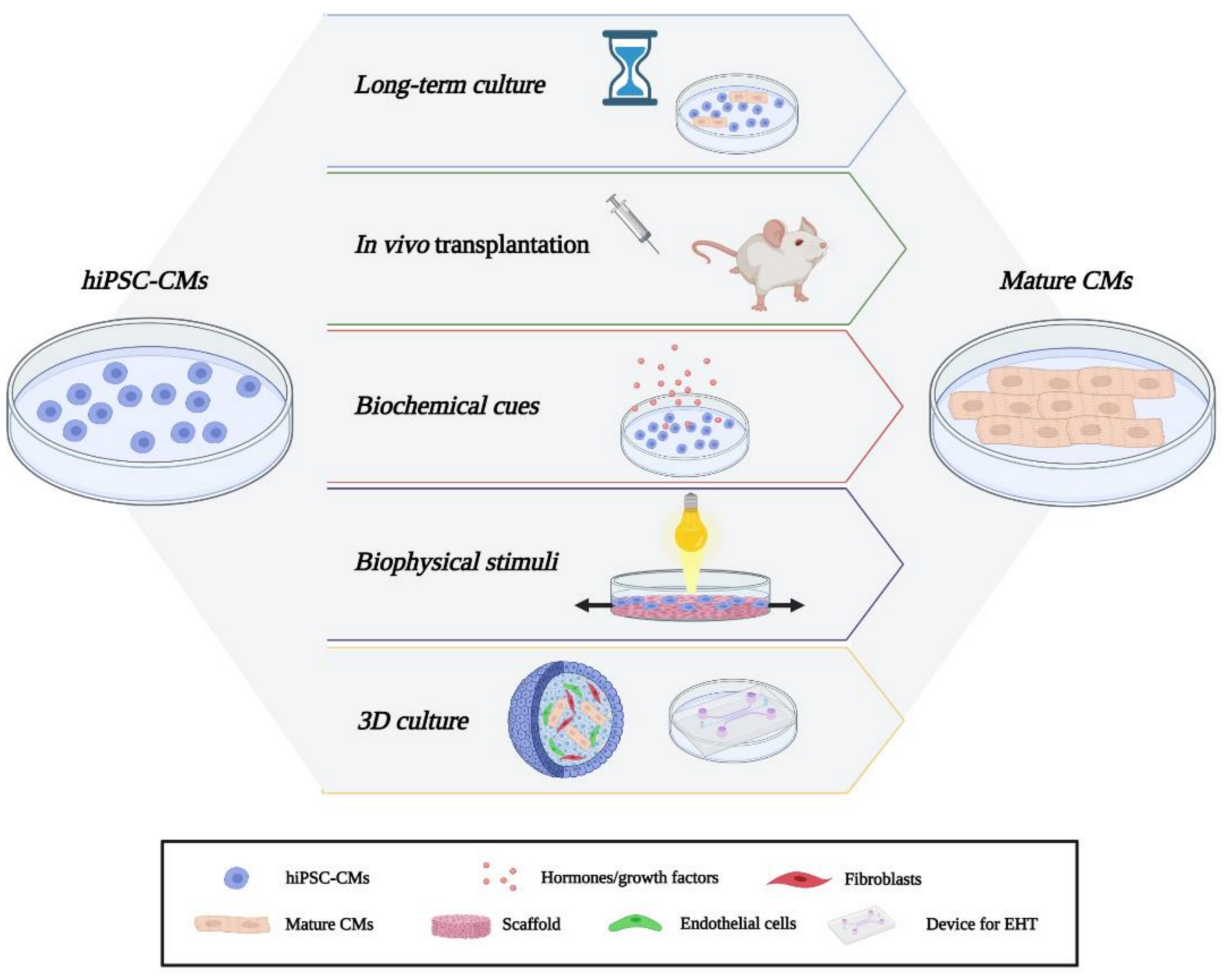

Figure 2. Overview of approaches to improve hiPSC-CMs maturation. Starting from the top: longterm culture condition; in vivo cell transplantation; biochemical induction by hormones/growth factors; biophysical modulation as occur for biomechanical and optogenetic stimuli, 3D multicellular structure generation, and EHT. 
In conclusion, we strongly believe that the advent of new methodologies, corroborated by the synergic combination of different expertise (i.e., biochemical, physical, chemical, material science), will allow obtaining hiPSC-CMs that will fully resemble the adult CMs phenotype, thus strengthening the applicability of the technology for the development of patient-specific therapies. The main achievement of in vitro cardiomyopathy modeling is thus to obtain more and more complex constructs, starting from genetic components and reproducing both the structure of the myocardium and its function and external stimuli while controlling modifiable factors to reduce the biological complexity of the system.

The necessity to improve reproducibility and scalability of cardiomyopathy in vitro models is still an unresolved clinical need to reduce the burden of these diseases. Cardiomyopathy high throughput models will become the main form of preclinical research and will bridge the gap towards clinical trials while reducing the tests on animal models.

Author Contributions: F.L. and A.S.M. Writing-Original Draft Preparation; F.L., C.M., D.M., V.C.D.G., I.S., E.S. and A.S.M. Writing-Review \& Editing. All authors have read and agreed to the published version of the manuscript.

Funding: A.S.M., E.S. and I.S. acknowledge financial support from the Italian Ministry of Health (RC2019 EF5C ID: 2754330).

Institutional Review Board Statement: Not applicable.

Informed Consent Statement: Not applicable.

Data Availability Statement: The data presented in this study are available on reasonable request from the corresponding author. The data are not publicly available due to privacy reasons.

Acknowledgments: The authors gratefully thank Maria Rosa Antognazza for constructive criticism of the manuscript. A.S.M. and E.S. are grateful to "Fondazione di Comunità di Milano" and "Fondo Giacomo Ponzone" for the support. Figures created with BioRender.com.

Conflicts of Interest: The funders had no role in the design of the study; in the collection, analyses, or interpretation of data; in the writing of the manuscript, or in the decision to publish the results.

\section{References}

1. Elliott, P.; Andersson, B.; Arbustini, E.; Bilinska, Z.; Cecchi, F.; Charron, P.; Dubourg, O.; Kuhl, U.; Maisch, B.; McKenna, W.J.; et al. Classification of the cardiomyopathies: A position statement from the European society Of cardiology working group on myocardial and pericardial diseases. Eur. Heart J. 2008, 29, 270-276. [CrossRef]

2. Maron, B.J.; Towbin, J.A.; Thiene, G.; Antzelevitch, C.; Corrado, D.; Arnett, D.; Moss, A.J.; Seidman, C.E.; Young, J.B. Contemporary definitions and classification of the cardiomyopathies: An american heart association scientific statement from the Council on Clinical Cardiology, Heart Failure and Transplantation Committee; Quality of Care and Outcomes Research and functional genomics and translational biology interdisciplinary working groups; and council on epidemiology and prevention. Circulation 2006, 113, 1807-1816. [CrossRef]

3. Fernandez-Falgueras, A.; Sarquella-Brugada, G.; Brugada, J.; Brugada, R.; Campuzano, O. Cardiac channelopathies and sudden death: Recent clinical and genetic advances. Biology 2017, 6, 7. [CrossRef]

4. Garcia-Elias, A.; Benito, B. Ion channel disorders and sudden cardiac death. Int. J. Mol. Sci. 2018, 19, 692. [CrossRef]

5. Moccia, F.; Lodola, F.; Stadiotti, I.; Pilato, C.A.; Bellin, M.; Carugo, S.; Pompilio, G.; Sommariva, E.; Maione, A.S. Calcium as a key player in arrhythmogenic cardiomyopathy: Adhesion disorder or intracellular alteration? Int. J. Mol. Sci. 2019, $20,3986$. [CrossRef]

6. Bergmann, O.; Zdunek, S.; Felker, A.; Salehpour, M.; Alkass, K.; Bernard, S.; Sjostrom, S.L.; Szewczykowska, M.; Jackowska, T.; Dos Remedios, C.; et al. Dynamics of cell generation and turnover in the human heart. Cell 2015, 161, 1566-1575. [CrossRef] [PubMed]

7. Zhou, P.; Pu, W.T. Recounting cardiac cellular composition. Circ. Res. 2016, 118, 368-370. [CrossRef]

8. Pinto, A.R.; Ilinykh, A.; Ivey, M.J.; Kuwabara, J.T.; D’Antoni, M.L.; Debuque, R.; Chandran, A.; Wang, L.; Arora, K.; Rosenthal, N.A.; et al. Revisiting cardiac cellular composition. Circ. Res. 2016, 118, 400-409. [CrossRef] [PubMed]

9. Nag, A.C. Study of non-muscle cells of the adult mammalian heart: A fine structural analysis and distribution. Cytobios 1980, 28, 41-61. [PubMed]

10. Tang, X.; Li, P.H.; Chen, H.Z. Cardiomyocyte senescence and cellular communications within myocardial microenvironments. Front. Endocrinol. 2020, 11, 280. [CrossRef] [PubMed] 
11. Pilato, C.A.; Stadiotti, I.; Maione, A.S.; Saverio, V.; Catto, V.; Tundo, F.; Dello Russo, A.; Tondo, C.; Pompilio, G.; Casella, M.; et al. Isolation and characterization of cardiac mesenchymal stromal cells from endomyocardial bioptic samples of arrhythmogenic cardiomyopathy patients. J. Vis. Exp. 2018, 132, e57263. [CrossRef] [PubMed]

12. Takahashi, K.; Yamanaka, S. Induction of pluripotent stem cells from mouse embryonic and adult fibroblast cultures by defined factors. Cell 2006, 126, 663-676. [CrossRef] [PubMed]

13. Zwi, L.; Caspi, O.; Arbel, G.; Huber, I.; Gepstein, A.; Park, I.H.; Gepstein, L. Cardiomyocyte differentiation of human induced pluripotent stem cells. Circulation 2009, 120, 1513-1523. [CrossRef]

14. Musunuru, K.; Sheikh, F.; Gupta, R.M.; Houser, S.R.; Maher, K.O.; Milan, D.J.; Terzic, A.; Wu, J.C. Induced pluripotent stem cells for cardiovascular disease modeling and precision medicine: A scientific statement from the American Heart Association. Circ. Genom. Precis. Med. 2018, 11, e000043. [CrossRef] [PubMed]

15. Meraviglia, V.; Arendzen, C.H.; Tok, M.; Freund, C.; Maione, A.S.; Sommariva, E.; Bellin, M. Generation of human induced pluripotent stem cell line LUMCi027-A and its isogenic gene-corrected line from a patient affected by arrhythmogenic cardiomyopathy and carrying the c.2013delC PKP2 mutation. Stem Cell Res. 2020, 46, 101835. [CrossRef]

16. Van Der Velden, J.; Klein, L.J.; Van Der Bijl, M.; Huybregts, M.A.; Stooker, W.; Witkop, J.; Eijsman, L.; Visser, C.; Visser, F.; Stienen, G. Force production in mechanically isolated cardiac myocytes from human ventricular muscle tissue. Cardiovasc. Res. 1998, 38, 414-423. [CrossRef]

17. Bird, S.D.; Doevendans, P.A.; Van Rooijen, M.A.; Brutel De La Riviere, A.; Hassink, R.J.; Passier, R.; Mummery, C.L. The human adult cardiomyocyte phenotype. Cardiovasc. Res. 2003, 58, 423-434. [CrossRef]

18. Wang, Q.; Lin, J.L.; Wu, K.H.; Wang, D.Z.; Reiter, R.S.; Sinn, H.W.; Lin, C.I.; Lin, C.J. Xin proteins and intercalated disc maturation, signaling and diseases. Front. Biosci. 2012, 17, 2566-2593. [CrossRef]

19. Snir, M.; Kehat, I.; Gepstein, A.; Coleman, R.; Itskovitz-Eldor, J.; Livne, E.; Gepstein, L. Assessment of the ultrastructural and proliferative properties of human embryonic stem cell-derived cardiomyocytes. Am. J. Physiol. Heart Circ. Physiol. 2003, 285, H2355-H2363. [CrossRef] [PubMed]

20. Kane, C.; Couch, L.; Terracciano, C.M. Excitation-contraction coupling of human induced pluripotent stem cell-derived cardiomyocytes. Front. Cell Dev. Biol. 2015, 3, 59. [CrossRef]

21. Scuderi, G.J.; Butcher, J. Naturally engineered maturation of cardiomyocytes. Front. Cell Dev. Biol. 2017, 5, 50. [CrossRef]

22. Crossman, D.J.; Young, A.A.; Ruygrok, P.N.; Nason, G.P.; Baddelely, D.; Soeller, C.; Cannell, M.B. T-tubule disease: Relationship between t-tubule organization and regional contractile performance in human dilated cardiomyopathy. J. Mol. Cell. Cardiol. 2015, 84, 170-178. [CrossRef] [PubMed]

23. Dai, D.F.; Danoviz, M.E.; Wiczer, B.; Laflamme, M.A.; Tian, R. Mitochondrial maturation in human pluripotent stem cell derived cardiomyocytes. Stem Cells Int. 2017, 2017, 5153625. [CrossRef] [PubMed]

24. Bartos, D.C.; Grandi, E.; Ripplinger, C.M. Ion channels in the heart. Compr. Physiol. 2015, 5, 1423-1464. [CrossRef] [PubMed]

25. Bett, G.C.; Kaplan, A.D.; Lis, A.; Cimato, T.R.; Tzanakakis, E.S.; Zhou, Q.; Morales, M.J.; Rasmusson, R.L. Electronic "expression" of the inward rectifier in cardiocytes derived from human-induced pluripotent stem cells. Heart Rhythm. 2013, 10, 1903-1910. [CrossRef]

26. Kim, J.J.; Yang, L.; Lin, B.; Zhu, X.; Sun, B.; Kaplan, A.D.; Bett, G.C.; Rasmusson, R.L.; London, B.; Salama, G. Mechanism of automaticity in cardiomyocytes derived from human induced pluripotent stem cells. J. Mol. Cell. Cardiol. 2015, 81, 81-93. [CrossRef]

27. Koivumaki, J.T.; Naumenko, N.; Tuomainen, T.; Takalo, J.; Oksanen, M.; Puttonen, K.A.; Lehtonen, S.; Kuusisto, J.; Laakso, M.; Koistinaho, J.; et al. Structural immaturity of human iPSC-derived cardiomyocytes: In silico investigation of effects on function and disease modeling. Front. Physiol. 2018, 9, 80. [CrossRef]

28. Cordeiro, J.M.; Nesterenko, V.V.; Sicouri, S.; Goodrow, R.J.; Treat, J.A.; Desai, M.; Wu, Y.; Doss, M.X.; Antzelevitch, C.; Di Diego, J.M. Identification and characterization of a transient outward $\mathrm{K}+$ current in human induced pluripotent stem cell-derived cardiomyocytes. J. Mol. Cell. Cardiol. 2013, 60, 36-46. [CrossRef]

29. Garg, P.; Garg, V.; Shrestha, R.; Sanguinetti, M.C.; Kamp, T.J.; Wu, J.C. Human induced pluripotent stem cell-derived cardiomyocytes as models for cardiac channelopathies: A primer for non-electrophysiologists. Circ. Res. 2018, 123, $224-243$. [CrossRef]

30. Lemoine, M.D.; Mannhardt, I.; Breckwoldt, K.; Prondzynski, M.; Flenner, F.; Ulmer, B.; Hirt, M.N.; Neuber, C.; Horvath, A.; Kloth, B.; et al. Human iPSC-derived cardiomyocytes cultured in 3D engineered heart tissue show physiological upstroke velocity and sodium current density. Sci. Rep. 2017, 7, 5464. [CrossRef]

31. Feyen, D.A.M.; McKeithan, W.L.; Bruyneel, A.A.N.; Spiering, S.; Hormann, L.; Ulmer, B.; Zhang, H.; Briganti, F.; Schweizer, M.; Hegyi, B.; et al. Metabolic maturation media improve physiological function of human iPSC-derived cardiomyocytes. Cell Rep. 2020, 32, 107925. [CrossRef]

32. Giacomelli, E.; Meraviglia, V.; Campostrini, G.; Cochrane, A.; Cao, X.; van Helden, R.W.J.; Krotenberg Garcia, A.; Mircea, M.; Kostidis, S.; Davis, R.P.; et al. Human-iPSC-derived cardiac stromal cells enhance maturation in 3D cardiac microtissues and reveal non-cardiomyocyte contributions to heart disease. Cell Stem Cell 2020, 26, 862-879.e811. [CrossRef]

33. Bers, D.M. Cardiac excitation-contraction coupling. Nature 2002, 415, 198-205. [CrossRef]

34. Gambardella, J.; Trimarco, B.; Iaccarino, G.; Santulli, G. New insights in cardiac calcium handling and excitation-contraction coupling. Adv. Exp. Med. Biol. 2018, 1067, 373-385. [CrossRef] 
35. Bedada, F.B.; Chan, S.S.; Metzger, S.K.; Zhang, L.; Zhang, J.; Garry, D.J.; Kamp, T.J.; Kyba, M.; Metzger, J.M. Acquisition of a quantitative, stoichiometrically conserved ratiometric marker of maturation status in stem cell-derived cardiac myocytes. Stem Cell Rep. 2014, 3, 594-605. [CrossRef]

36. Chen, R.; He, J.; Wang, Y.; Guo, Y.; Zhang, J.; Peng, L.; Wang, D.; Lin, Q.; Zhang, J.; Guo, Z.; et al. Qualitative transcriptional signatures for evaluating the maturity degree of pluripotent stem cell-derived cardiomyocytes. Stem Cell Res. Ther. 2019, 10, 113. [CrossRef] [PubMed]

37. Cho, G.S.; Lee, D.I.; Tampakakis, E.; Murphy, S.; Andersen, P.; Uosaki, H.; Chelko, S.; Chakir, K.; Hong, I.; Seo, K.; et al. Neonatal transplantation confers maturation of PSC-derived cardiomyocytes conducive to modeling cardiomyopathy. Cell Rep. 2017, 18, 571-582. [CrossRef]

38. Kamakura, T.; Makiyama, T.; Sasaki, K.; Yoshida, Y.; Wuriyanghai, Y.; Chen, J.; Hattori, T.; Ohno, S.; Kita, T.; Horie, M.; et al. Ultrastructural maturation of human-induced pluripotent stem cell-derived cardiomyocytes in a long-term culture. Circ. J. 2013, 77, 1307-1314. [CrossRef]

39. Lundy, S.D.; Zhu, W.Z.; Regnier, M.; Laflamme, M.A. Structural and functional maturation of cardiomyocytes derived from human pluripotent stem cells. Stem Cells Dev. 2013, 22, 1991-2002. [CrossRef] [PubMed]

40. Funakoshi, S.; Miki, K.; Takaki, T.; Okubo, C.; Hatani, T.; Chonabayashi, K.; Nishikawa, M.; Takei, I.; Oishi, A.; Narita, M.; et al. Enhanced engraftment, proliferation, and therapeutic potential in heart using optimized human iPSC-derived cardiomyocytes. Sci. Rep. 2016, 6, 19111. [CrossRef] [PubMed]

41. Caspi, O.; Huber, I.; Kehat, I.; Habib, M.; Arbel, G.; Gepstein, A.; Yankelson, L.; Aronson, D.; Beyar, R.; Gepstein, L. Transplantation of human embryonic stem cell-derived cardiomyocytes improves myocardial performance in infarcted rat hearts. J. Am. Coll. Cardiol. 2007, 50, 1884-1893. [CrossRef]

42. Chong, J.J.; Yang, X.; Don, C.W.; Minami, E.; Liu, Y.W.; Weyers, J.J.; Mahoney, W.M.; Van Biber, B.; Cook, S.M.; Palpant, N.J.; et al. Human embryonic-stem-cell-derived cardiomyocytes regenerate non-human primate hearts. Nature 2014, 510, $273-277$. [CrossRef]

43. Kadota, S.; Pabon, L.; Reinecke, H.; Murry, C.E. In vivo maturation of human induced pluripotent stem cell-derived cardiomyocytes in neonatal and adult rat hearts. Stem Cell Rep. 2017, 8, 278-289. [CrossRef]

44. Yang, X.; Rodriguez, M.; Pabon, L.; Fischer, K.A.; Reinecke, H.; Regnier, M.; Sniadecki, N.J.; Ruohola-Baker, H.; Murry, C.E. Tri-iodo-l-thyronine promotes the maturation of human cardiomyocytes-derived from induced pluripotent stem cells. J. Mol. Cell. Cardiol. 2014, 72, 296-304. [CrossRef] [PubMed]

45. Parikh, S.S.; Blackwell, D.J.; Gomez-Hurtado, N.; Frisk, M.; Wang, L.; Kim, K.; Dahl, C.P.; Fiane, A.; Tonnessen, T.; Kryshtal, D.O.; et al. Thyroid and glucocorticoid hormones promote functional T-tubule development in human-induced pluripotent stem cell-derived cardiomyocytes. Circ. Res. 2017, 121, 1323-1330. [CrossRef]

46. Rupert, C.E.; Coulombe, K.L.K. IGF1 and NRG1 enhance proliferation, metabolic maturity, and the force-frequency response in hESC-derived engineered cardiac tissues. Stem Cells Int. 2017, 2017, 7648409. [CrossRef]

47. Mills, R.J.; Titmarsh, D.M.; Koenig, X.; Parker, B.L.; Ryall, J.G.; Quaife-Ryan, G.A.; Voges, H.K.; Hodson, M.P.; Ferguson, C.; Drowley, L.; et al. Functional screening in human cardiac organoids reveals a metabolic mechanism for cardiomyocyte cell cycle arrest. Proc. Natl. Acad. Sci. USA 2017, 114, E8372-E8381. [CrossRef] [PubMed]

48. Yang, X.; Rodriguez, M.L.; Leonard, A.; Sun, L.; Fischer, K.A.; Wang, Y.; Ritterhoff, J.; Zhao, L.; Kolwicz, S.C.; Pabon, L.; et al. Fatty acids enhance the maturation of cardiomyocytes derived from human pluripotent stem cells. Stem Cell Rep. 2019, 13, 657-668. [CrossRef] [PubMed]

49. Correia, C.; Koshkin, A.; Duarte, P.; Hu, D.; Teixeira, A.; Domian, I.; Serra, M.; Alves, P.M. Distinct carbon sources affect structural and functional maturation of cardiomyocytes derived from human pluripotent stem cells. Sci. Rep. 2017, 7, 8590. [CrossRef] [PubMed]

50. Kim, J.W.; Tchernyshyov, I.; Semenza, G.L.; Dang, C.V. HIF-1-mediated expression of pyruvate dehydrogenase kinase: A metabolic switch required for cellular adaptation to hypoxia. Cell Metab. 2006, 3, 177-185. [CrossRef]

51. Menendez-Montes, I.; Escobar, B.; Palacios, B.; Gomez, M.J.; Izquierdo-Garcia, J.L.; Flores, L.; Jimenez-Borreguero, L.J.; Aragones, J.; Ruiz-Cabello, J.; Torres, M.; et al. Myocardial VHL-HIF signaling controls an embryonic metabolic switch essential for cardiac maturation. Dev. Cell 2016, 39, 724-739. [CrossRef]

52. Gasiorowski, J.Z.; Murphy, C.J.; Nealey, P.F. Biophysical cues and cell behavior: The big impact of little things. Annu. Rev. Biomed. Eng. 2013, 15, 155-176. [CrossRef] [PubMed]

53. Ribeiro, A.J.; Ang, Y.S.; Fu, J.D.; Rivas, R.N.; Mohamed, T.M.; Higgs, G.C.; Srivastava, D.; Pruitt, B.L. Contractility of single cardiomyocytes differentiated from pluripotent stem cells depends on physiological shape and substrate stiffness. Proc. Natl. Acad. Sci. USA 2015, 112, 12705-12710. [CrossRef]

54. Herron, T.J.; Rocha, A.M.; Campbell, K.F.; Ponce-Balbuena, D.; Willis, B.C.; Guerrero-Serna, G.; Liu, Q.; Klos, M.; Musa, H.; Zarzoso, M.; et al. Extracellular matrix-mediated maturation of human pluripotent stem cell-derived cardiac monolayer structure and electrophysiological function. Circ. Arrhythm Electrophysiol. 2016, 9, e003638. [CrossRef] [PubMed]

55. Vuorenpaa, H.; Penttinen, K.; Heinonen, T.; Pekkanen-Mattila, M.; Sarkanen, J.R.; Ylikomi, T.; Aalto-Setala, K. Maturation of human pluripotent stem cell derived cardiomyocytes is improved in cardiovascular construct. Cytotechnology 2017, 69, 785-800. [CrossRef] 
56. Lyra-Leite, D.M.; Petersen, A.P.; Ariyasinghe, N.R.; Cho, N.; McCain, M.L. Mitochondrial architecture in cardiac myocytes depends on cell shape and matrix rigidity. J. Mol. Cell. Cardiol. 2021, 150, 32-43. [CrossRef]

57. Macadangdang, J.; Guan, X.; Smith, A.S.; Lucero, R.; Czerniecki, S.; Childers, M.K.; Mack, D.L.; Kim, D.H. Nanopatterned human iPSC-based model of a dystrophin-null cardiomyopathic phenotype. Cell. Mol. Bioeng. 2015, 8, 320-332. [CrossRef]

58. Rao, C.; Prodromakis, T.; Kolker, L.; Chaudhry, U.A.; Trantidou, T.; Sridhar, A.; Weekes, C.; Camelliti, P.; Harding, S.E.; Darzi, A.; et al. The effect of microgrooved culture substrates on calcium cycling of cardiac myocytes derived from human induced pluripotent stem cells. Biomaterials 2013, 34, 2399-2411. [CrossRef]

59. Kim, D.H.; Lipke, E.A.; Kim, P.; Cheong, R.; Thompson, S.; Delannoy, M.; Suh, K.Y.; Tung, L.; Levchenko, A. Nanoscale cues regulate the structure and function of macroscopic cardiac tissue constructs. Proc. Natl. Acad. Sci. USA 2010, 107, 565-570. [CrossRef] [PubMed]

60. Werley, C.A.; Chien, M.P.; Gaublomme, J.; Shekhar, K.; Butty, V.; Yi, B.A.; Kralj, J.M.; Bloxham, W.; Boyer, L.A.; Regev, A.; et al. Geometry-dependent functional changes in iPSC-derived cardiomyocytes probed by functional imaging and RNA sequencing. PLoS ONE 2017, 12, e0172671. [CrossRef]

61. Chan, Y.C.; Ting, S.; Lee, Y.K.; Ng, K.M.; Zhang, J.; Chen, Z.; Siu, C.W.; Oh, S.K.; Tse, H.F. Electrical stimulation promotes maturation of cardiomyocytes derived from human embryonic stem cells. J. Cardiovasc. Transl. Res. 2013, 6, 989-999. [CrossRef]

62. Kroll, K.; Chabria, M.; Wang, K.; Hausermann, F.; Schuler, F.; Polonchuk, L. Electro-mechanical conditioning of human iPSCderived cardiomyocytes for translational research. Prog. Biophys. Mol. Biol. 2017, 130, 212-222. [CrossRef] [PubMed]

63. Ma, R.; Liang, J.; Huang, W.; Guo, L.; Cai, W.; Wang, L.; Paul, C.; Yang, H.T.; Kim, H.W.; Wang, Y. Electrical stimulation enhances cardiac differentiation of human induced pluripotent stem cells for myocardial infarction therapy. Antioxid. Redox Signal. 2018, 28, 371-384. [CrossRef]

64. Dwenger, M.; Kowalski, W.J.; Masumoto, H.; Nakane, T.; Keller, B.B. Chronic optogenetic pacing of human-induced pluripotent stem cell-derived engineered cardiac tissues. Methods Mol. Biol. 2021, 2191, 151-169. [CrossRef] [PubMed]

65. Ellingsen, O.; Davidoff, A.J.; Prasad, S.K.; Berger, H.J.; Springhorn, J.P.; Marsh, J.D.; Kelly, R.A.; Smith, T.W. Adult rat ventricular myocytes cultured in defined medium: Phenotype and electromechanical function. Am. J. Physiol. 1993, 265, H747-H754. [CrossRef] [PubMed]

66. Kim, C.; Majdi, M.; Xia, P.; Wei, K.A.; Talantova, M.; Spiering, S.; Nelson, B.; Mercola, M.; Chen, H.S. Non-cardiomyocytes influence the electrophysiological maturation of human embryonic stem cell-derived cardiomyocytes during differentiation. Stem Cells Dev. 2010, 19, 783-795. [CrossRef] [PubMed]

67. Yoshida, S.; Miyagawa, S.; Fukushima, S.; Kawamura, T.; Kashiyama, N.; Ohashi, F.; Toyofuku, T.; Toda, K.; Sawa, Y. Maturation of human induced pluripotent stem cell-derived cardiomyocytes by soluble factors from human mesenchymal stem cells. Mol. Ther. 2018, 26, 2681-2695. [CrossRef] [PubMed]

68. Maione, A.S.; Pilato, C.A.; Casella, M.; Gasperetti, A.; Stadiotti, I.; Pompilio, G.; Sommariva, E. Fibrosis in arrhythmogenic cardiomyopathy: The phantom Thread in the fibro-adipose tissue. Front. Physiol. 2020, 11, 279. [CrossRef]

69. Maione, A.S.; Stadiotti, I.; Pilato, C.A.; Perrucci, G.L.; Saverio, V.; Catto, V.; Vettor, G.; Casella, M.; Guarino, A.; Polvani, G.; et al. Excess TGF-beta1 drives cardiac mesenchymal stromal cells to a pro-fibrotic commitment in arrhythmogenic cardiomyopathy. Int. J. Mol. Sci. 2021, 22, 2673. [CrossRef]

70. Huethorst, E.; Hortigon, M.; Zamora-Rodriguez, V.; Reynolds, P.M.; Burton, F.; Smith, G.; Gadegaard, N. Enhanced humaninduced pluripotent stem cell derived cardiomyocyte maturation using a dual microgradient substrate. ACS Biomater. Sci. Eng. 2016, 2, 2231-2239. [CrossRef]

71. Correia, C.; Koshkin, A.; Duarte, P.; Hu, D.; Carido, M.; Sebastiao, M.J.; Gomes-Alves, P.; Elliott, D.A.; Domian, I.J.; Teixeira, A.P.; et al. 3D aggregate culture improves metabolic maturation of human pluripotent stem cell derived cardiomyocytes. Biotechnol. Bioeng. 2018, 115, 630-644. [CrossRef]

72. Ulmer, B.M.; Stoehr, A.; Schulze, M.L.; Patel, S.; Gucek, M.; Mannhardt, I.; Funcke, S.; Murphy, E.; Eschenhagen, T.; Hansen, A. Contractile work contributes to maturation of energy metabolism in hiPSC-derived cardiomyocytes. Stem Cell Rep. 2018, 10, 834-847. [CrossRef]

73. Silbernagel, N.; Korner, A.; Balitzki, J.; Jaggy, M.; Bertels, S.; Richter, B.; Hippler, M.; Hellwig, A.; Hecker, M.; Bastmeyer, M.; et al. Shaping the heart: Structural and functional maturation of iPSC-cardiomyocytes in 3D-micro-scaffolds. Biomaterials 2020, 227, 119551. [CrossRef] [PubMed]

74. Zhang, B.; Montgomery, M.; Chamberlain, M.D.; Ogawa, S.; Korolj, A.; Pahnke, A.; Wells, L.A.; Masse, S.; Kim, J.; Reis, L.; et al. Biodegradable scaffold with built-in vasculature for organ-on-a-chip engineering and direct surgical anastomosis. Nat. Mater. 2016, 15, 669-678. [CrossRef]

75. Gao, L.; Kupfer, M.E.; Jung, J.P.; Yang, L.; Zhang, P.; Da Sie, Y.; Tran, Q.; Ajeti, V.; Freeman, B.T.; Fast, V.G.; et al. Myocardial tissue engineering with cells derived from human-induced pluripotent stem cells and a native-like, high-resolution, 3-dimensionally printed scaffold. Circ. Res. 2017, 120, 1318-1325. [CrossRef]

76. Feiner, R.; Engel, L.; Fleischer, S.; Malki, M.; Gal, I.; Shapira, A.; Shacham-Diamand, Y.; Dvir, T. Engineered hybrid cardiac patches with multifunctional electronics for online monitoring and regulation of tissue function. Nat. Mater. 2016, 15, 679-685. [CrossRef] [PubMed]

77. Filippo Buono, M.; von Boehmer, L.; Strang, J.; Hoerstrup, S.P.; Emmert, M.Y.; Nugraha, B. Human cardiac organoids for modeling genetic cardiomyopathy. Cells 2020, 9, 1733. [CrossRef] [PubMed] 
78. Li, R.A.; Keung, W.; Cashman, T.J.; Backeris, P.C.; Johnson, B.V.; Bardot, E.S.; Wong, A.O.T.; Chan, P.K.W.; Chan, C.W.Y.; Costa, K.D. Bioengineering an electro-mechanically functional miniature ventricular heart chamber from human pluripotent stem cells. Biomaterials 2018, 163, 116-127. [CrossRef]

79. Giacomelli, E.; Bellin, M.; Sala, L.; van Meer, B.J.; Tertoolen, L.G.; Orlova, V.V.; Mummery, C.L. Three-dimensional cardiac microtissues composed of cardiomyocytes and endothelial cells co-differentiated from human pluripotent stem cells. Development 2017, 144, 1008-1017. [CrossRef] [PubMed]

80. Scesa, G.; Adami, R.; Bottai, D. iPSC preparation and epigenetic memory: Does the tissue origin matter? Cells 2021, 10, 1470. [CrossRef] [PubMed]

81. Kim, K.; Doi, A.; Wen, B.; Ng, K.; Zhao, R.; Cahan, P.; Kim, J.; Aryee, M.J.; Ji, H.; Ehrlich, L.I.; et al. Epigenetic memory in induced pluripotent stem cells. Nature 2010, 467, 285-290. [CrossRef]

82. Meraviglia, V.; Wen, J.; Piacentini, L.; Campostrini, G.; Wang, C.; Florio, M.C.; Azzimato, V.; Fassina, L.; Langes, M.; Wong, J.; et al. Higher cardiogenic potential of iPSCs derived from cardiac versus skin stromal cells. Front. Biosci. 2016, 21, 719-743. [CrossRef]

83. Davis, R.P.; Casini, S.; van den Berg, C.W.; Hoekstra, M.; Remme, C.A.; Dambrot, C.; Salvatori, D.; Oostwaard, D.W.; Wilde, A.A.; Bezzina, C.R.; et al. Cardiomyocytes derived from pluripotent stem cells recapitulate electrophysiological characteristics of an overlap syndrome of cardiac sodium channel disease. Circulation 2012, 125, 3079-3091. [CrossRef]

84. Garg, P.; Oikonomopoulos, A.; Chen, H.; Li, Y.; Lam, C.K.; Sallam, K.; Perez, M.; Lux, R.L.; Sanguinetti, M.C.; Wu, J.C. Genome editing of induced pluripotent stem cells to decipher cardiac channelopathy variant. J. Am. Coll. Cardiol. 2018, $72,62-75$. [CrossRef]

85. Itzhaki, I.; Maizels, L.; Huber, I.; Gepstein, A.; Arbel, G.; Caspi, O.; Miller, L.; Belhassen, B.; Nof, E.; Glikson, M.; et al. Modeling of catecholaminergic polymorphic ventricular tachycardia with patient-specific human-induced pluripotent stem cells. J. Am. Coll. Cardiol. 2012, 60, 990-1000. [CrossRef]

86. Daly, A.C.; Davidson, M.D.; Burdick, J.A. 3D bioprinting of high cell-density heterogeneous tissue models through spheroid fusion within self-healing hydrogels. Nat. Commun. 2021, 12, 753. [CrossRef]

87. Arai, K.; Murata, D.; Verissimo, A.R.; Mukae, Y.; Itoh, M.; Nakamura, A.; Morita, S.; Nakayama, K. Fabrication of scaffold-free tubular cardiac constructs using a Bio-3D printer. PLoS ONE 2018, 13, e209162. [CrossRef] [PubMed]

88. Mummery, C.L.; Zhang, J.; Ng, E.S.; Elliott, D.A.; Elefanty, A.G.; Kamp, T.J. Differentiation of human embryonic stem cells and induced pluripotent stem cells to cardiomyocytes: A methods overview. Circ. Res. 2012, 111, 344-358. [CrossRef] [PubMed]

89. Lee, J.H.; Protze, S.I.; Laksman, Z.; Backx, P.H.; Keller, G.M. Human pluripotent stem cell-derived atrial and ventricular cardiomyocytes develop from distinct mesoderm populations. Cell Stem Cell 2017, 21, 179-194.e174. [CrossRef] [PubMed]

90. Litvinukova, M.; Talavera-Lopez, C.; Maatz, H.; Reichart, D.; Worth, C.L.; Lindberg, E.L.; Kanda, M.; Polanski, K.; Heinig, M.; Lee, M.; et al. Cells of the adult human heart. Nature 2020, 588, 466-472. [CrossRef]

91. Ariyasinghe, N.R.; Lyra-Leite, D.M.; McCain, M.L. Engineering cardiac microphysiological systems to model pathological extracellular matrix remodeling. Am. J. Physiol. Heart Circ. Physiol. 2018, 315, H771-H789. [CrossRef]

92. Itzhaki, I.; Maizels, L.; Huber, I.; Zwi-Dantsis, L.; Caspi, O.; Winterstern, A.; Feldman, O.; Gepstein, A.; Arbel, G.; Hammerman, H.; et al. Modelling the long QT syndrome with induced pluripotent stem cells. Nature 2011, 471, 225-229. [CrossRef] [PubMed]

93. Karakikes, I.; Termglinchan, V.; Wu, J.C. Human-induced pluripotent stem cell models of inherited cardiomyopathies. Curr. Opin. Cardiol. 2014, 29, 214-219. [CrossRef] [PubMed]

94. Mosqueira, D.; Smith, J.G.W.; Bhagwan, J.R.; Denning, C. Modeling hypertrophic cardiomyopathy: Mechanistic insights and pharmacological intervention. Trends Mol. Med. 2019, 25, 775-790. [CrossRef]

95. Park, S.J.; Zhang, D.; Qi, Y.; Li, Y.; Lee, K.Y.; Bezzerides, V.J.; Yang, P.; Xia, S.; Kim, S.L.; Liu, X.; et al. Insights into the pathogenesis of catecholaminergic polymorphic ventricular tachycardia from engineered human heart tissue. Circulation 2019, 140, 390-404. [CrossRef]

96. Rhee, J.W.; Yi, H.; Thomas, D.; Lam, C.K.; Belbachir, N.; Tian, L.; Qin, X.; Malisa, J.; Lau, E.; Paik, D.T.; et al. Modeling secondary iron overload cardiomyopathy with human induced pluripotent stem cell-derived cardiomyocytes. Cell Rep. 2020, $32,107886$. [CrossRef]

97. Vikhorev, P.G.; Vikhoreva, N.N. Cardiomyopathies and related changes in contractility of human heart muscle. Int. J. Mol. Sci. 2018, 19, 2234. [CrossRef] [PubMed]

98. Sommariva, E.; Brambilla, S.; Carbucicchio, C.; Gambini, E.; Meraviglia, V.; Dello Russo, A.; Farina, F.M.; Casella, M.; Catto, V.; Pontone, G.; et al. Cardiac mesenchymal stromal cells are a source of adipocytes in arrhythmogenic cardiomyopathy. Eur. Heart J. 2016, 37, 1835-1846. [CrossRef]

99. Johansson, M.; Ulfenborg, B.; Andersson, C.X.; Heydarkhan-Hagvall, S.; Jeppsson, A.; Sartipy, P.; Synnergren, J. Cardiac hypertrophy in a dish: A human stem cell based model. Biol. Open 2020, 9, bio052381. [CrossRef]

100. Stadiotti, I.; Lippi, M.; Maione, A.S.; Compagnucci, P.; Andreini, D.; Casella, M.; Pompilio, G.; Sommariva, E. Cardiac biomarkers and autoantibodies in endurance athletes: Potential similarities with arrhythmogenic cardiomyopathy pathogenic mechanisms. Int. J. Mol. Sci. 2021, 22, 6500. [CrossRef]

101. Oyama, K.; Mizuno, A.; Shintani, S.A.; Itoh, H.; Serizawa, T.; Fukuda, N.; Suzuki, M.; Ishiwata, S. Microscopic heat pulses induce contraction of cardiomyocytes without calcium transients. Biochem. Biophys. Res. Commun. 2012, 417, 607-612. [CrossRef] 
102. Huang, Z.; Xu, J.; Chen, J.; Chen, H.; Wang, H.; Huang, Z.; Chen, Y.; Lu, X.; Lu, F.; Hu, J. Photoacoustic stimulation promotes the osteogenic differentiation of bone mesenchymal stem cells to enhance the repair of bone defect. Sci. Rep. 2017, 7, 15842. [CrossRef] [PubMed]

103. Maziarz, A.; Kocan, B.; Bester, M.; Budzik, S.; Cholewa, M.; Ochiya, T.; Banas, A. How electromagnetic fields can influence adult stem cells: Positive and negative impacts. Stem Cell Res. Ther. 2016, 7, 54. [CrossRef]

104. Romanenko, S.; Begley, R.; Harvey, A.R.; Hool, L.; Wallace, V.P. The interaction between electromagnetic fields at megahertz, gigahertz and terahertz frequencies with cells, tissues and organisms: Risks and potential. J. R. Soc. Interface 2017, 14, 20170585. [CrossRef] [PubMed]

105. Di Maria, F.; Lodola, F.; Zucchetti, E.; Benfenati, F.; Lanzani, G. The evolution of artificial light actuators in living systems: From planar to nanostructured interfaces. Chem. Soc. Rev. 2018, 47, 4757-4780. [CrossRef] [PubMed]

106. Lee, H.P.; Gaharwar, A.K. Light-responsive inorganic biomaterials for biomedical applications. Adv. Sci. 2020, 7, 2000863. [CrossRef]

107. Milos, F.; Tullii, G.; Gobbo, F.; Lodola, F.; Galeotti, F.; Verpelli, C.; Mayer, D.; Maybeck, V.; Offenhausser, A.; Antognazza, M.R. High aspect ratio and light-sensitive micropillars based on a semiconducting polymer optically regulate neuronal growth. ACS Appl. Mater. Interfaces 2021, 13, 23438-23451. [CrossRef]

108. Tullii, G.; Giona, F.; Lodola, F.; Bonfadini, S.; Bossio, C.; Varo, S.; Desii, A.; Criante, L.; Sala, C.; Pasini, M.; et al. High-aspect-ratio semiconducting polymer pillars for 3D cell cultures. ACS Appl. Mater. Interfaces 2019, 11, 28125-28137. [CrossRef] [PubMed]

109. Sero, J.E.; Stevens, M.M. Nanoneedle-based materials for intracellular studies. Adv. Exp. Med. Biol. 2021, 1295, 191-219. [CrossRef] [PubMed]

110. Lodola, F.; Rosti, V.; Tullii, G.; Desii, A.; Tapella, L.; Catarsi, P.; Lim, D.; Moccia, F.; Antognazza, M.R. Conjugated polymers optically regulate the fate of endothelial colony-forming cells. Sci. Adv. 2019, 5, eaav4620. [CrossRef]

111. Abdel Aziz, I.; Malferrari, M.; Roggiani, F.; Tullii, G.; Rapino, S.; Antognazza, M.R. Light-triggered electron transfer between a conjugated polymer and cytochrome $C$ for optical modulation of redox signaling. iScience 2020, 23, 101091. [CrossRef] [PubMed]

112. Antognazza, M.R.; Abdel Aziz, I.; Lodola, F. Use of exogenous and endogenous photomediators as efficient ROS modulation tools: Results and perspectives for therapeutic purposes. Oxid. Med. Cell. Longev. 2019, 2019, 2867516. [CrossRef] [PubMed]

113. Ilaria Abdel Aziz, I.A.; Antognazza, M.R. Wireless nanotechnologies light up the next frontier in cell Calcium signalling. MRS Adv. 2020, 5, 3473-3489. [CrossRef]

114. Santoro, R.; Perrucci, G.L.; Gowran, A.; Pompilio, G. Unchain my heart: Integrins at the basis of iPSC cardiomyocyte differentiation. Stem Cells Int. 2019, 2019, 8203950. [CrossRef] [PubMed] 